\title{
Medical cannabis use in the United States: a retrospective database study
}

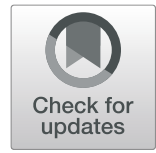

\author{
V. Kishan Mahabir, Jamil J. Merchant, Christopher Smith ${ }^{*}$ and Alisha Garibaldi(D)
}

\begin{abstract}
Introduction: Growing interest in the medicinal properties of cannabis has led to an increase in its use to treat medical conditions, and the establishment of state-specific medical cannabis programs. Despite medical cannabis being legal in 33 states and the District of Colombia, there remains a paucity of data characterizing the patients accessing medical cannabis programs.

Methods: We retrospectively reviewed a registry with data from 33 medical cannabis evaluation clinics in the United States, owned and operated by CB2 Insights. Data were collected primarily by face-to-face interviews for patients seeking medical cannabis certification between November 18, 2018 and March 18, 2020. Patients were removed from the analysis if they did not have a valid date of birth, were less than 18 , or did not have a primary medical condition reported; a total of 61,379 patients were included in the analysis. Data were summarized using descriptive statistics expressed as a mean (standard deviation (SD)) or median (interquartile range (IQR)) as appropriate for continuous variables, and number (percent) for categorical variables. Statistical tests performed across groups included t-tests, chi-squared tests and regression.
\end{abstract}

Results: The average age of patients was $45.5,54.8 \%$ were male and the majority were Caucasian (87.5\%). Female patients were significantly older than males (47.0 compared to 44.6). Most patients reported cannabis experience prior to seeking medical certification (66.9\%). The top three mutually exclusive primary medical conditions reported were unspecified chronic pain (38.8\%), anxiety (13.5\%) and post-traumatic stress disorder (PTSD) (8.4\%). The average number of comorbid conditions reported was 2.7, of which anxiety was the most common (28.3\%). Females reported significantly more comorbid conditions than males (3.1 compared to 2.3).

Conclusion: This retrospective study highlighted the range and number of conditions for which patients in the US seek medical cannabis. Rigorous clinical trials investigating the use of medical cannabis to treat pain conditions, anxiety, insomnia, depression and PTSD would benefit a large number of patients, many of whom use medical cannabis to treat multiple conditions.

Keywords: Medical cannabis, Chronic pain, Anxiety, Post-traumatic stress disorder, Gender

\section{Background}

The cannabis plant has been used in traditional medicine for centuries, and within the last few decades it has generated considerable attention among the general population, modern medical community and regulatory bodies for its potential medicinal capabilities (Alsherbiny and Li 2018). The effects of cannabis are due to the action of

\footnotetext{
* Correspondence: Christopher.smith@cb2insights.com

CB2 Insights, 5045 Orbitor Dr, Building 11, Suite 300, Mississauga, ON L4W $4 Y 4$, Canada
}

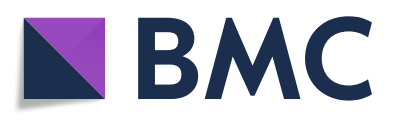

( The Author(s). 2020 Open Access This article is licensed under a Creative Commons Attribution 4.0 International License, which permits use, sharing, adaptation, distribution and reproduction in any medium or format, as long as you give

appropriate credit to the original author(s) and the source, provide a link to the Creative Commons licence, and indicate if changes were made. The images or other third party material in this article are included in the article's Creative Commons licence, unless indicated otherwise in a credit line to the material. If material is not included in the article's Creative Commons licence and your intended use is not permitted by statutory regulation or exceeds the permitted use, you will need to obtain permission directly from the copyright holder. To view a copy of this licence, visit http://creativecommons.org/licenses/by/4.0/.

cannabinoids, a diverse group of chemical compounds found in the cannabis plant that act on the human endocannabinoid system, via a series of interactions with cell receptors throughout the human body, and alter neurotransmitter release in the brain affecting various physiological functions (Fraguas-Sanchez and Torres-Suarez 2018; Vuckovic et al. 2018). While more than 100 cannabinoids have been identified, $\Delta$-9-tetrahydrocannabinol (THC) and cannabidiol (CBD) have undergone the most scientific investigation and are considered to be the 
greatest contributors to the medicinal effects of cannabis (Pertwee et al. 2010; Pertwee 1997).

The growing interest in medical cannabis has led to an increase in its use to treat medical conditions or symptoms thereof, such as chronic pain, anxiety, and depression. Individuals do this either through self-medication, accessing the drug via the recreational or illicit markets, or via medical cannabis programs in regions where regulations permit. Other clinical conditions that cannabis is thought to treat include multiple sclerosis, AIDS-associated wasting/cachexia, insomnia, arthritis, epilepsy, post-traumatic stress disorder (PTSD), glaucoma, headaches and migraines, and nausea (Kosiba et al. 2019; Lu and Anderson 2017; Kaur et al. 2016; Zaller et al. 2015; Klumpers and Thacker 2019; Institute of Medicine (U.S.) 1999).

Medical cannabis programs began in the United States (US) in 1996, with California becoming the first state to legalize medical cannabis (Legislatures NC of S 2020). Since then, other states have slowly adopted medical cannabis programs, with the programs themselves evolving over time. As of 2000, 8 states had legalized medical cannabis (Yu et al. 2020); by 2010, there were 16 and by 2016, there were 29 (Pacula and Smart 2017). As of July 2020, medical cannabis is legal in 33 states and the District of Columbia, 12 of which allow adults over the age of 21 to use cannabis recreationally (DISA Global Solutions 2019).

Qualifying conditions for medical cannabis vary significantly state-by-state as some states (e.g., California, Massachusetts, Oklahoma, and the District of Columbia) allow physicians to use discretion when recommending patients for certification, while other states only allow certification based on a limited set of qualifying conditions (Legislatures NC of S 2020). The allowable THCpercentage component of state-run programs also varies, with certain states only allowing access to high-CBD, low-THC products for medical cannabis patients. Patients seeking medical cannabis in the US in most states are required to obtain a state-specific medical cannabis identification card, allowing them to purchase cannabis products from dispensaries to treat certain medical conditions.

Despite medical cannabis being legal in many states, there remains a paucity of data characterizing the patients accessing it via state-run programs. Two large studies reviewed available state registry data of patients holding medical cannabis licenses; however, these studies came with limitations including voluntary reporting at the state-level, or inability for the authors to access the registry data (Boehnke et al. 2019; Fairman 2016). One of the studies reviewed the primary conditions for which patients sought medical cannabis, but did not report any other patient characteristics such as age or gender (Boehnke et al. 2019). The other reported on the age and gender of patients accessing medical cannabis, but did not report on medical conditions (Fairman 2016). While useful, these studies did not adequately characterize medical cannabis use through state programs by age, gender or condition. Other studies that have been published to characterize medical cannabis patients are limited by sample size and selection, include only patient-reported data, or include patients outside of the US (Sexton et al. 2016; Eurich et al. 2019; BonnMiller et al. 2014; Reinarman et al. 2011).

Given the need for a large data set to contribute to the medical knowledge, inform on policy and identify areas for future research, we designed a retrospective study of a registry database. The primary objective of this study was to thoroughly describe the population of patients seeking treatment with medical cannabis in the US. These data were reviewed at a high-level to answer the following questions:

1. What are the key demographic characteristics of patients accessing medical cannabis?

2. Are there differences in characteristics of males and females accessing medical cannabis?

3. What are the most commonly reported conditions among this sample of patients?

4. How many conditions do patients seek treatment for, and does this change based on age and gender?

These questions were investigated to assist the medical community in further developing an understanding of patients seeking medical cannabis for treatment of their conditions and symptoms, and to assist others in determining areas of interest for future research. This knowledge may also inform policy makers in states considering medical cannabis legalization or the further development of existing medical cannabis programs in states where medical cannabis has already been legalized.

\section{Methods}

This was a retrospective database study of patients seeking medical cannabis certification in the US. Data were extracted from the database software utilized in CB2 Insights' clinical network. CB2 Insights operates one of the largest collections of medical cannabis evaluation clinics in the US, collectively assessing approximately 100,000 patients per year seeking access to medical cannabis, using a single and consistent software that contributes data to a patient registry. These 33 independent clinics are not connected to dispensaries or producers of medical cannabis, and are situated across 12 states (number of clinics): Colorado (6), Connecticut (1), Delaware (2), Illinois (1), Maine (1), Maryland (1), Massachusetts (10), Missouri (1), New Jersey (5), New York (1), Rhode Island (2), and Pennsylvania (2). Patients access these clinics by 
physician-referral or self-referral through word of mouth, community out-reach and marketing. Over $95 \%$ of data were collected via face-to-face interview, with the remaining collected via telemedicine. Patients presenting to any of the clinics are required to complete the same baseline information upon intake, including demographic, medical, and therapeutic information; however, certain characteristics such as race and gender were not made mandatory initially, and are not reported for all patients. Baseline questions include patient-reported tobacco smoking and alcohol use, current or past substance abuse of drugs and/or alcohol, use of illicit (illegal) drugs, medication use and alternative therapies. Medication use is an open-ended question that may be completed by transcribing a medication list into the software, which leaves room for errors and may be a limitation of the data. All patients indicate their primary reason for seeking access to medical cannabis and are asked to report all comorbid conditions for which they are also seeking medical cannabis. Patients are required to provide supporting documentation of their medical histories and relevant conditions for review and verification, in the form of medical records or a letter from another physician. Review of medical documentation, in combination with a medical evaluation by a state-authorized physician or nurse practitioner are used to confirm their qualification for medical cannabis within their respective state. Prior to data export, the protocol was reviewed by the Advarra Institutional Review Board (IRB) and was determined to be exempt from IRB oversight (Pro00042652) as the study had minimal risk, the data exports were void of patient identifiers, and it did not require direct patient contact.

Data were exported for 62,145 patients who were seen for their initial assessment between November 18, 2018 (when the technology and standardized protocol were introduced into the clinics) and March 18, 2020. Data were exported without any patient identifiers to ensure patient anonymity. Eligibility criteria were applied to the data set and the following patients were removed: 1) 77 patients without a valid date of birth; 2) 78 patients younger than 18; and 3) 611 patients without a primary medical condition reported. Overall, 61,379 patients were included in the analysis (Fig. 1).

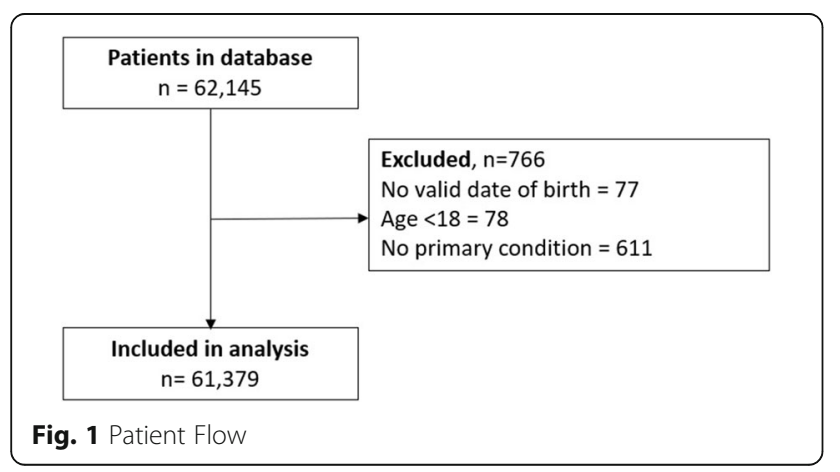

Data from the database software utilized in CB2 Insights' clinical network were also merged with US tax data, which provides tabulations of income tax data by ZIP code in order to estimate household income based on individual patients' ZIP codes. Median household income values from the 2018 dataset purchased from Cubit Planning Inc. were used (US Income Statistics - Current Census Data for Zip Codes 2018). Cubit Planning Inc. summarizes the most current income statistics from the US Census Bureau.

When a final dataset was confirmed, data were analyzed using RStudio (Boston, MA). All information was summarized using descriptive statistics expressed as a mean (standard deviation (SD)) or median (interquartile range (IQR)) as appropriate for continuous variables, and number (percent) for categorical variables. Univariate analyses were conducted to inform multivariate analyses including t-tests when comparing means and chi-squared tests when comparing proportions. Regression analyses were conducted to determine if age and gender, specifically, were significant predictors of characteristics of smoking, alcohol consumption, prior cannabis use and medication usage, the number of medications being used, and the number of conditions reported. Logistic regression was used for dichotomous variables and linear regression was used for continuous variables. To analyze whether age and gender were significant predictors of reporting each primary condition, each condition was compared separately to all others using logistic regression. An interaction model with age and gender was included for all regression analyses; if the interaction effect was significant, $p$-values are reported for the interaction model, otherwise $\mathrm{p}$-values are reported for the model without interaction. All tests were completed with a significance level of 0.05 . $P$-values less than 0.001 are expressed as $p<0.001$, and $95 \%$ confidence intervals $(\mathrm{CI})$ are provided where appropriate.

\section{Results}

The average age of patients in the sample was $45.5(\mathrm{SD}=$ 15.8 ) and $54.8 \%$ were male (Table 1 ). The average age of females, 47.0 $(\mathrm{SD}=15.7)$, was significantly greater than males, 44.6 $(\mathrm{SD}=15.7)(p<0.001$, difference in means $=$ 2.4, 95\% CI: 2.15-2.68) (Table 2). Of the patients with race reported, Caucasians represented the largest group of the sample population at $87.5 \%$. The median household income in the ZIP code in which patients resided was available for 56,083 patients. The overwhelming majority of patients lived in a ZIP code where the median household income was above $\$ 40,000$ (93.7\%); the median was $\$ 69,481$ (IQR \$35,807). Most patients (66.9\%) reported that they had experience with cannabis prior to seeking medical certification, were non-smokers (81.2\%), did not drink (57.5\%) and did not have a history of substance abuse (94.4\%). Gender was not a significant predictor of reporting prior cannabis experience or history of 
Table 1 Sociodemographic and medical characteristics of 61,379 patients seeking medical cannabis certification from CB2 Insights evaluation clinics

\begin{tabular}{ll}
\hline Characteristic & Patients $(n=61,379)$ \\
& Mean (SD) or $n(\%)$
\end{tabular}

\begin{tabular}{ll}
\hline Age (years), mean (SD) & $45.5(15.8)$ \\
Gender & \\
Male & $33,651(54.8 \%)$ \\
Female & $23,209(37.8 \%)$ \\
Non-binary & $33(0.1 \%)$ \\
Unknown & $4486(7.3 \%)$
\end{tabular}

Race $(n=32,275)$

White/Caucasian

Black/African American

Other

Asian

American Indian/Alaska Native

Middle Eastern

Native Hawaiian or Other Pacific Islander

South East Asian

$28,322(87.5 \%)$

$2738(8.5 \%)$

$518(1.6 \%)$

$277(0.9 \%)$

$261(0.8 \%)$

$63(0.2 \%)$

$58(0.2 \%)$

$38(0.1 \%)$

Surrogate Household Income $(n=56,083)$

$$
\begin{aligned}
& <\$ 20,000 \\
& \$ 20,000-<\$ 40,000 \\
& \$ 40,000-<\$ 60,000 \\
& \$ 60,000-<\$ 80,000 \\
& \$ \$ 80,000-<\$ 100,000 \\
& >\$ 100,000
\end{aligned}
$$

Smoking Status

Smoker

Non-smoker

Alcohol Consumption

$$
\text { Yes }
$$

No

Previous Cannabis Experience

Yes

No

Use of Non-Cannabis Illicit Drugs

$$
\text { Yes }
$$

No

History of Substance Abuse

$$
\text { Yes }
$$

No

Number of Medications

0

1
41,070 (66.9\%)

$61,105(99.6 \%)$

3426 (5.6\%)

$57,943(94.4 \%)$

$34,273(55.8 \%)$

$7866(12.8 \%)$

4755 (7.7\%)

3515 (5.7\%)
20,309 (33.1\%)

$274(0.4 \%)$

Table 1 Sociodemographic and medical characteristics of 61,379 patients seeking medical cannabis certification from CB2 Insights evaluation clinics (Continued)

\begin{tabular}{ll}
\hline Characteristic & $\begin{array}{l}\text { Patients }(\boldsymbol{n}=\mathbf{6 1 , 3 7 9 )} \\
\text { Mean (SD) or } \mathbf{n}(\%)\end{array}$ \\
\hline 4 & $2372(3.9 \%)$ \\
$5+$ & $8598(14.0 \%)$ \\
Alternate Therapies & \\
Exercise & $25,831(42.1 \%)$ \\
Massage therapy & $13,250(21.6 \%)$ \\
Mental health counselling & $11,235(18.3 \%)$ \\
Chiropractor & $11,047(18.0 \%)$ \\
Acupuncture & $5632(9.2 \%)$ \\
Mindfulness-based cognitive therapy & $5176(8.4 \%)$ \\
Aroma therapy & $3849(6.3 \%)$ \\
Cognitive behavioural therapy & $3470(5.7 \%)$ \\
Physiotherapy & $3380(5.5 \%)$ \\
Homeopathic medicine & $3186(5.2 \%)$ \\
Reiki & $2329(3.8 \%)$ \\
Naturopathic medicine & $1788(2.9 \%)$ \\
Addictions counselling & $1158(1.9 \%)$ \\
Other & $221(0.4 \%)$ \\
None & $24,939(40.6 \%)$ \\
Number of Comorbid Conditions & \\
0 & $10,807(17.6 \%)$ \\
4 & $15,971(26.0 \%)$ \\
\hline+ & $9863(16.1 \%)$ \\
\hline & $7319(11.9 \%)$ \\
\hline & $5497(9.0 \%)$ \\
\hline & $11,922(19.4 \%)$ \\
\hline & \\
\hline &
\end{tabular}

Table 1 summarizes key patient characteristics of the entire sample of 61,379 patients who received medical cannabis certification at clinics owned and operated by CB2 Insights. For characteristics in which data were not available for every patient, a sample size for that variable is provided. $\mathrm{SD}=$ standard deviation

substance abuse ( $p=0.929$ and 0.871 , respectively), but was for smoking status and alcohol consumption $(p<0.001)$ (Tables 3 and 4). Males reported smoking tobacco more than females, whereas females reported the use of alcohol more than males.

Less than half of patients reported prescription medication use (44.2\%). Increased age and female gender were significant predictors of reporting at least one medication $(p<0.001)$ and a greater number of medications $(\mathrm{p}<0.001)$ (Tables 3 and 4). Of patients who reported taking at least one medication $(n=27,106)$, the mean number of medications reported was $4.1(\mathrm{SD}=3.7)$. Over half the sample (59.4\%) reported currently using an alternate form of therapy. Of those who reported using a therapy, the average number reported was $2.5(\mathrm{SD}=1.7)$, and the most 
Table 2 Univariate analysis of differences of key characteristics of 61,379 patients seeking medical cannabis certification by age

\begin{tabular}{lll}
\hline Characteristic & $\begin{array}{l}\text { Average } \\
\text { Age (SD) }\end{array}$ & $\begin{array}{l}\text { p-value, 95\% } \\
\text { Cl around the } \\
\text { difference } \\
\text { in means }\end{array}$ \\
\hline Gender & & \\
Male & $44.6(15.7)$ & $<0.001$ \\
Female & $47.0(15.7)$ & $2.15-2.68$ \\
Smoking Status & & \\
Smoker & $42.6(13.8)$ & $<0.001$ \\
Non-smoker & $46.2(16.1)$ & $3.28-3.86$ \\
Alcohol Consumption & & 0.004 \\
Yes & $45.7(15.6)$ & $0.06-0.12$ \\
No & $45.3(15.9)$ & \\
Previous Cannabis Experience & & $<0.001$ \\
Yes & $45.1(15.5)$ & $0.80-1.42$ \\
No & $46.3(16.4)$ & \\
History of Substance Abuse & & $<0.001$ \\
Yes & $42.5(13.7)$ & $2.70-3.65$ \\
No & $45.7(15.9)$ & \\
Medication Usage & & \\
None & $42.9(15.5)$ & \\
At least one & $48.8(15.6)$ & \\
\hline
\end{tabular}

Table 2 summarizes the analysis of differences of key patient characteristics by age. T-tests were conducted for differences in average age for all characteristics. SD standard deviation, $\mathrm{Cl}$ confidence interval. $\mathrm{Cls}$ are provided around the differences in the means

commonly reported among this group were exercise (70.9\%), massage therapy (36.4\%), mental health counselling (30.8\%) and chiropractor (30.3\%). A quarter of the sample (26.1\%) did not report any current use of medications or alternate therapy.

Regardless of gender, the top three primary medical conditions were unspecified chronic pain $(n=23,817$, $38.8 \%)$, anxiety ( $n=8280,13.5 \%)$ and PTSD $(n=5143,8.4 \%)$ (Table 5). Following the top three were back and neck problems $(n=3969,6.5 \%)$, arthritis $(n=2395,3.9 \%)$, insomnia $(n=2096,3.4 \%)$ and cancer-related pain $(n=1641,2.7 \%)$. Depression, migraines, muscle spasms, ADD/ADHD, chronic nausea, fibromyalgia, headaches and epilepsy were each reported as the primary medical condition for $2.0 \%$ or less of the sample. Of the primary medical conditions, $10.6 \%$ of those reported were other medical conditions each representing less than $1.0 \%$ of the entire sample. Gender was not a significant predictor of epilepsy, but was a significant predictor for all other conditions (Table 6); females were significantly more likely to report anxiety, PTSD, arthritis, cancer related pain, depression, migraines, chronic nausea, fibromyalgia and headaches, whereas males were significantly more likely to report unspecified chronic pain, back \& neck problems, insomnia, muscle spasms and ADD/ADHD.
Table 3 Univariate analysis of differences of key characteristics of 56,860 patients seeking medical cannabis certification by gender

\begin{tabular}{|c|c|c|c|}
\hline \multirow[t]{2}{*}{ Characteristic } & \multirow{2}{*}{$\begin{array}{l}\text { Male } \\
n=33,651 \\
\mathrm{n}(\%) \text { or } \\
\text { mean (SD) }\end{array}$} & \multirow{2}{*}{$\begin{array}{l}\text { Female } \\
n=23,209 \\
\mathrm{n}(\%) \text { or } \\
\text { mean (SD) }\end{array}$} & \multirow[t]{2}{*}{$\begin{array}{l}\mathrm{p}- \\
\text { value }\end{array}$} \\
\hline & & & \\
\hline \multicolumn{4}{|l|}{ Smoking Status } \\
\hline Smoker & 6619 (19.7\%) & $4063(17.5 \%)$ & \multirow[t]{2}{*}{$<0.001$} \\
\hline Non-smoker & $27,032(80.3 \%)$ & $19,146(82.5 \%)$ & \\
\hline \multicolumn{4}{|l|}{ Alcohol Consumption } \\
\hline Yes & $13,880(41.2 \%)$ & $9971(43.0 \%)$ & \multirow[t]{2}{*}{$<0.001$} \\
\hline No & $19,771(58.8 \%)$ & $13,238(57.0 \%)$ & \\
\hline \multicolumn{4}{|l|}{ Previous Cannabis Experience } \\
\hline Yes & $23,553(70.0 \%)$ & $15,474(66.7 \%)$ & \multirow[t]{2}{*}{$<0.001$} \\
\hline No & $10,098(30.0 \%)$ & 7735 (33.3\%) & \\
\hline \multicolumn{4}{|l|}{ History of Substance Abuse } \\
\hline Yes & $2092(6.2 \%)$ & $997(4.3 \%)$ & \multirow[t]{2}{*}{$<0.001$} \\
\hline No & $31,559(93.8 \%)$ & $22,212(95.7 \%)$ & \\
\hline \multicolumn{4}{|l|}{ Medication Usage } \\
\hline None & $21,268(63.2 \%)$ & $11,010(47.4 \%)$ & \multirow[t]{2}{*}{$<0.001$} \\
\hline At least one & $12,383(36.8 \%)$ & $12,199(52.6 \%)$ & \\
\hline $\begin{array}{l}\text { Average Number of } \\
\text { Medications* }(n=27,106)\end{array}$ & $4.0(3.6)$ & $4.4(3.7)$ & $<0.001$ \\
\hline Average Number of Conditions & $3.3(2.3)$ & $4.1(2.9)$ & $<0.001$ \\
\hline
\end{tabular}

Table 3 summarizes the univariate analysis of differences of key patient characteristics by gender among 56,860 patients for whom gender was reported. Percentages are calculated from the sample size for each respective column. Chi-squared tests were conducted for differences in proportions of males and females for all characteristics, except average number of medications and average number of conditions, in which t-tests were conducted. $\mathrm{SD}=$ standard deviation. *Average number of medications is calculated for those reporting at least one medication $(n=27,106)$

Patients reporting anxiety, PTSD, depression, migraines, $\mathrm{ADD} / \mathrm{ADHD}$, chronic nausea, headaches or epilepsy as their primary reason for seeking medical cannabis were significantly more likely to be younger $(p<0.001)$, whereas patients seeking medical cannabis primarily for unspecified chronic pain, back and neck problems, arthritis, insomnia, cancer related pain or fibromyalgia were significantly more likely to be older (Table 6). Age was not a significant predictor of reporting muscle spasms.

Patients were able to report any number of comorbid medical conditions necessary to describe their reason(s) for seeking medical cannabis (Table 7). The average number of comorbid medical conditions reported was 2.7 $(\mathrm{SD}=2.6)$. Anxiety was the most commonly reported comorbid condition $(n=17,359,28.3 \%)$, followed by back and neck problems $(n=14,550,23.7 \%)$, insomnia $(n=14$, $247,23.2 \%)$, depression $(n=13,413,21.9 \%)$, and unspecified chronic pain $(n=11,199,18.2 \%)$. Only $17.6 \%$ of the sample did not report a comorbid medical condition. 
Table 4 Multivariate analysis results of differences of key characteristics of 56,860 patients seeking medical cannabis certification by gender and age, with and without interaction

\begin{tabular}{|c|c|c|c|c|}
\hline \multirow[b]{2}{*}{ Characteristic } & \multicolumn{2}{|c|}{ Model without interaction between age and gender } & \multicolumn{2}{|c|}{ Model with interaction between age and gender } \\
\hline & Coefficient $(95 \% \mathrm{Cl})$ & p-value & Coefficient $(95 \% \mathrm{Cl})$ & p-value \\
\hline \multicolumn{5}{|l|}{ Smoking Status } \\
\hline Intercept & $-0.890(-0.961,-0.820)$ & $<0.001$ & $-1.00(-1.108,-0.900)$ & $<0.001$ \\
\hline Age & $-0.014(-0.016,-0.013)$ & $<0.001$ & $-0.012(-0.014,-0.010)$ & $<0.001$ \\
\hline Gender (male) & $0.110(0.066,0.153)$ & $<0.001$ & $0.294(0.163,0.426)$ & $<0.001$ \\
\hline Interaction & NA & NA & $-0.004(-0.007,-0.001)$ & 0.004 \\
\hline \multicolumn{5}{|c|}{ Alcohol Consumption } \\
\hline Intercept & $-0.368(-0.424,-0.311)$ & $<0.001$ & $-0.220(-0.302,-0.138)$ & $<0.001$ \\
\hline Age & $0.002(0.001,0.003)$ & $<0.001$ & $-0.001(-0.003,0.000)$ & 0.108 \\
\hline Gender (male) & $-0.066(-0.100,-0.032)$ & $<0.001$ & $-0.312(-0.417,-0.207)$ & $<0.001$ \\
\hline Interaction & NA & NA & $0.005(0.003,0.007)$ & $<0.001$ \\
\hline \multicolumn{5}{|c|}{ Previous Cannabis Experience } \\
\hline Intercept & $0.904(0.844,0.964)$ & $<0.001$ & $0.992(0.905,1.08)$ & $<0.001$ \\
\hline Age & $-0.004(-0.006,-0.003)$ & $<0.001$ & $-0.006(-0.008,-0.005)$ & $<0.001$ \\
\hline Gender (male) & $0.143(0.107,0.179)$ & $<0.001$ & $-0.005(-0.117,0.107)$ & 0.929 \\
\hline Interaction & NA & NA & $0.003(0.001,0.005)$ & 0.006 \\
\hline \multicolumn{5}{|c|}{ History of Substance Abuse } \\
\hline Intercept & $-2.540(-2.664,-2.418)$ & $<0.001$ & $-2.284(-2.475,-2.095)$ & $<0.001$ \\
\hline Age & $-0.012(-0.015,-0.010)$ & $<0.001$ & $-0.018(-0.022,-0.014)$ & $<0.001$ \\
\hline Gender (male) & $0.361(0.284,0.439)$ & $<0.001$ & $-0.019(-0.249,0.212)$ & 0.871 \\
\hline Interaction & NA & NA & $0.009(0.004,0.014)$ & 0.001 \\
\hline \multicolumn{5}{|l|}{ Medication Usage } \\
\hline Intercept & $-1.014(-1.072,-0.957)$ & $<0.001$ & $-0.595(-0.677,-0.513)$ & $<0.001$ \\
\hline Age & $0.024(0.023,0.025)$ & $<0.001$ & $0.015(0.013,0.017)$ & $<0.001$ \\
\hline Gender (male) & $-0.607(-0.642,-0.573)$ & $<0.001$ & $-1.336(-1.445,-1.227)$ & $<0.001$ \\
\hline Interaction & NA & NA & $0.016(0.013,0.018)$ & $<0.001$ \\
\hline \multicolumn{5}{|c|}{ Average Number of Medications } \\
\hline Intercept & $0.236(0.214,0.259)$ & $<0.001$ & $0.356(0.324,0.389)$ & $<0.001$ \\
\hline Age & $0.011(0.011,0.012)$ & $<0.001$ & $0.009(0.008,0.009)$ & $<0.001$ \\
\hline Gender (male) & $-0.233(-0.247,-0.220)$ & $<0.001$ & $-0.432(-0.473,-0.391)$ & $<0.001$ \\
\hline Interaction & NA & NA & $0.004(0.003,0.005)$ & $<0.001$ \\
\hline \multicolumn{5}{|c|}{ Average Number of Conditions } \\
\hline Intercept & $1.483(1.469,1.497)$ & $<0.001$ & $1.507(1.487,1.527)$ & $<0.001$ \\
\hline Age & $0.000(0.000,0.000)$ & 0.423 & $-0.001(-0.001,0.000)$ & 0.003 \\
\hline Gender (male) & $-0.143(-0.151,-0.135)$ & $<0.001$ & $-0.183(-0.209,-0.157)$ & $<0.001$ \\
\hline Interaction & NA & NA & $0.001(0.000,0.001)$ & 0.001 \\
\hline
\end{tabular}

Table 4 shows the results of regression analysis for age and gender as predictors for variables analyzed with univariate analysis in Tables 2 and 3 among 56,860 patients for whom gender was reported. Results are presented with and without an interaction between age and gender included in the model. The coefficient column represents the magnitude of effect and direction of the predictor variable; a negative coefficient for age suggests that younger patients are more likely to report the characteristic, and a negative coefficient for gender suggests that females are more likely to report the characteristic. $\mathrm{Cl}$ confidence interval

Taking into consideration all medical conditions reported (both primary and comorbid (Table 7)), over half of the sample reported unspecified chronic pain $(57.0 \%)$, followed by anxiety (41.8\%), back and neck problems (30.2\%), insomnia (26.6\%) and depression
(23.9\%). Patients reported an average of 3.7 total medical conditions $(\mathrm{SD}=2.6)$. Younger age and female gender were significant predictors of the number of conditions patients reported ( $p=0.003$ and $p<0.001$, respectively). Females reported an average of $4.1(\mathrm{SD}=2.9)$ total 
Table 5 Primary medical condition reported by 61,379 patients seeking medical cannabis certification, by gender

\begin{tabular}{llll}
\hline Primary Condition & Patients, $\mathbf{n}(\%)$ & Male, $\mathbf{n}(\%)$ & $\begin{array}{l}\text { Female, } \mathbf{n}(\%) \\
\mathbf{n = 2 3 , 2 0 9}\end{array}$ \\
\hline Unspecified Chronic Pain & $\mathbf{n = 6 1 , 3 7 9}$ & $\mathbf{n = 3 3 , 6 5 1}$ & $8710(37.5 \%)$ \\
Anxiety & $23,817(38.8 \%)$ & $14,164(42.1 \%)$ & $3224(13.9 \%)$ \\
Post Traumatic Stress Disorder & $8280(13.5 \%)$ & $2879(11.7 \%)$ & $1982(8.5 \%)$ \\
Back \& Neck Problems & $5143(8.4 \%)$ & $2506(7.4 \%)$ & $1125(4.8 \%)$ \\
Arthritis & $3969(6.5 \%)$ & $1149(3.4 \%)$ & $1048(4.5 \%)$ \\
Insomnia & $2395(3.9 \%)$ & $1187(3.5 \%)$ & $673(2.9 \%)$ \\
Cancer Related Pain & $2096(3.4 \%)$ & $782(2.3 \%)$ & $722(3.1 \%)$ \\
Depression & $1641(2.7 \%)$ & $575(1.7 \%)$ & $470(2.0 \%)$ \\
Migraines & $1249(2.0 \%)$ & $499(1.5 \%)$ & $656(2.8 \%)$ \\
Muscle Spasms & $1245(2.0 \%)$ & $624(1.9 \%)$ & $384(1.7 \%)$ \\
ADD/ADHD & $1038(1.7 \%)$ & $624(1.9 \%)$ & $235(1.0 \%)$ \\
Chronic Nausea & $1002(1.6 \%)$ & $477(1.4 \%)$ & $419(1.8 \%)$ \\
Fibromyalgia & $926(1.5 \%)$ & $70(0.2 \%)$ & $597(2.6 \%)$ \\
Headaches & $726(1.2 \%)$ & $356(1.1 \%)$ & $307(1.3 \%)$ \\
Epilepsy & $707(1.2 \%)$ & $372(1.1 \%)$ & $224(1.0 \%)$ \\
Other & $626(1.0 \%)$ & $3443(10.2 \%)$ & $2433(10.5 \%)$ \\
\hline
\end{tabular}

Table 5 presents a summary of the individuals reporting each primary condition overall and by gender. Patients could only report one primary condition. Any condition representing less than $1.0 \%$ was grouped as an "other". A list of "other" primary conditions is available in Table 8 . Percentages are calculated from the sample size for each respective column. $A D D$ attention deficit disorder, $A D H D$ attention deficit hyperactivity disorder

conditions, compared to an average of $3.3(\mathrm{SD}=2.3)$ among males.

\section{Discussion}

We conducted an extensive retrospective study with the objective of describing the population of patients seeking treatment with medical cannabis at 33 clinics in the US. Our results indicate that patients seeking medical cannabis in the US most commonly report suffering from unspecified chronic pain (57.0\%), regardless of age or gender, which is consistent with similar studies that report 61.2 to $82.6 \%$ of patients seeking medical cannabis for chronic pain (Boehnke et al. 2019; Sexton et al. 2016; Eurich et al. 2019; Reinarman et al. 2011). Second to unspecified chronic pain, patients were most likely to report anxiety as their primary medical condition, and anxiety was the most commonly reported comorbid condition. This finding is consistent with results from a survey completed by Sexton et al. among self-identifying medical cannabis patients, in which the second and third most common medical conditions that patients reported using medical cannabis for were anxiety (58.1\%) and depression (50.3\%) (Sexton et al. 2016). Gender was a significant predictor for most primary conditions, which is unsurprising as males and females have different risk factors, experiences and perceptions of illness and do not tend to report or be diagnosed with medical conditions in equal proportions (Seeman 1997; Buvinić et al. 2006; Westergaard et al. 2019).
The average number of conditions and comorbidities is not commonly stated, but has been reported at 1.8 and 3.0 in similar studies, both lower than our findings (Reinarman et al. 2011; Salazar et al. 2019). The average number of conditions reported differed between males and females, with females reporting a higher average number of conditions. This aligns with previous research that has demonstrated that females access health care services more than males and may be more diligent with providing relevant information, which may partially explain why females tend to have higher reported rates of morbidity (Bertakis et al. 2000; Verbrugge and Wingard 1987; Waldron 1983; MacIntyre et al. 1999).

Similar to the survey by Salazar et al., this study also demonstrated the wide variety of conditions for which patients access medical cannabis (Salazar et al. 2019). Conditions representing less than $1.0 \%$ of sample accounted for $10.6 \%$ of primary conditions reported and included more than 200 unique conditions (Table 8), the majority of which came from states where physicians are able to use their discretion for patients' qualification (MA, $\mathrm{MD}, \mathrm{ME}, \mathrm{MO})$. The information on the number and variety of conditions for which patients report seeking medical cannabis treatment is important for medical practitioners for several reasons. Firstly, it highlights the breadth of conditions for which patients are seeking medical cannabis for symptomatic relief. This is important as it identifies patients who may potentially turn to them with questions regarding their suitability for medical 
Table 6 Multivariate analysis results of differences in primary condition reported by 56,860 patients seeking medical cannabis certification by gender and age, with and without interaction

\begin{tabular}{|c|c|c|c|c|}
\hline \multirow{2}{*}{$\begin{array}{l}\text { Primary } \\
\text { Condition }\end{array}$} & \multicolumn{2}{|c|}{ Model without interaction between age and gender } & \multicolumn{2}{|c|}{ Model with interaction between age and gender } \\
\hline & Coefficient $(95 \% \mathrm{Cl})$ & p-value & Coefficient $(95 \% \mathrm{Cl})$ & p-value \\
\hline \multicolumn{5}{|c|}{ Unspecified Chronic Pain } \\
\hline Intercept & $-0.500(-0.557,-0.443)$ & $<0.001$ & $-0.647(-0.731,-0.563)$ & $<0.001$ \\
\hline Age & $0.000(-0.001,0.001)$ & 0.700 & $0.003(0.001,0.005)$ & 0.001 \\
\hline Gender (Male) & $0.190(0.156,0.224)$ & $<0.001$ & $0.430(0.323,0.536)$ & $<0.001$ \\
\hline Interaction & NA & NA & $-0.005(-0.007,-0.003)$ & $<0.001$ \\
\hline \multicolumn{5}{|l|}{ Anxiety } \\
\hline Intercept & $-1.047(-1.128,-0.966)$ & $<0.001$ & $-0.972(-1.085,-0.859)$ & $<0.001$ \\
\hline Age & $-0.017(-0.019,-0.015)$ & $<0.001$ & $-0.019(-0.021,-0.016)$ & $<0.001$ \\
\hline Gender (Male) & $-0.236(-0.286,-0.185)$ & $<0.001$ & $-0.369(-0.519,-0.220)$ & $<0.001$ \\
\hline Interaction & NA & NA & $0.003(0.000,0.006)$ & 0.064 \\
\hline \multicolumn{5}{|c|}{ Post Traumatic Stress Disorder } \\
\hline Intercept & $-1.345(-1.442,-1.249)$ & $<0.001$ & $-0.873(-1.011,-0.737)$ & $<0.001$ \\
\hline Age & $-0.023(-0.025,-0.021)$ & $<0.001$ & $-0.034(-0.038,-0.031)$ & $<0.001$ \\
\hline Gender (Male) & $-0.054(-0.114,0.006)$ & 0.079 & $-0.846(-1.024,-0.669)$ & $<0.001$ \\
\hline Interaction & NA & NA & $0.019(0.015,0.023)$ & $<0.001$ \\
\hline \multicolumn{5}{|c|}{ Back \& Neck Problems } \\
\hline Intercept & $-3.718(-3.841,-3.596)$ & $<0.001$ & $-3.772(-3.977,-3.571)$ & $<0.001$ \\
\hline Age & $0.015(0.013,0.017)$ & $<0.001$ & $0.016(0.012,0.020)$ & $<0.001$ \\
\hline Gender (Male) & $0.495(0.423,0.568)$ & $<0.001$ & $0.572(0.333,0.814)$ & $<0.001$ \\
\hline Interaction & NA & NA & $-0.002(-0.006,0.003)$ & 0.508 \\
\hline \multicolumn{5}{|l|}{ Arthritis } \\
\hline Intercept & $-6.013(-6.201,-5.828)$ & $<0.001$ & $-6.081(-6.355,-5.813)$ & $<0.001$ \\
\hline Age & $0.056(0.053,0.059)$ & $<0.001$ & $0.057(0.052,0.061)$ & $<0.001$ \\
\hline Gender (Male) & $-0.179(-0.266,-0.092)$ & $<0.001$ & $-0.057(-0.417,0.304)$ & 0.755 \\
\hline Interaction & NA & NA & $-0.002(-0.008,0.004)$ & 0.493 \\
\hline \multicolumn{5}{|l|}{ Insomnia } \\
\hline Intercept & $-3.980(-4.143,-3.818)$ & $<0.001$ & $-4.620(-4.892,-4.355)$ & $<0.001$ \\
\hline Age & $0.010(0.007,0.013)$ & $<0.001$ & $0.022(0.017,0.027)$ & $<0.001$ \\
\hline Gender (Male) & $0.226(0.130,0.323)$ & $<0.001$ & $1.190(0.871,1.513)$ & $<0.001$ \\
\hline Interaction & NA & NA & $-0.020(-0.026,-0.013)$ & $<0.001$ \\
\hline \multicolumn{5}{|c|}{ Cancer Related Pain } \\
\hline Intercept & $-6.200(-6.421,-5.983)$ & $<0.001$ & $-5.679(-5.978,-5.388)$ & $<0.001$ \\
\hline Age & $0.052(0.049,0.056)$ & $<0.001$ & $0.043(0.038,0.048)$ & $<0.001$ \\
\hline Gender (Male) & $-0.192(-0.296,-0.088)$ & $<0.001$ & $-1.184(-1.604,-0.764)$ & $<0.001$ \\
\hline Interaction & NA & NA & $0.017(0.010,0.024)$ & $<0.001$ \\
\hline \multicolumn{5}{|l|}{ Depression } \\
\hline Intercept & $-3.026(-3.225,-2.830)$ & $<0.001$ & $-3.007(-3.282,-2.738)$ & $<0.001$ \\
\hline Age & $-0.019(-0.023,-0.015)$ & $<0.001$ & $-0.019(-0.026,-0.013)$ & $<0.001$ \\
\hline Gender (Male) & $-0.218(-0.341,-0.094)$ & 0.001 & $-0.253(-0.616,0.111)$ & 0.173 \\
\hline Interaction & NA & NA & $0.001(-0.007,0.009$ & 0.842 \\
\hline \multicolumn{5}{|l|}{ Migraines } \\
\hline Intercept & $-2.621(-2.805,-2.438)$ & $<0.001$ & $-2.689(-2.923,-2.459)$ & $<0.001$ \\
\hline
\end{tabular}


Table 6 Multivariate analysis results of differences in primary condition reported by 56,860 patients seeking medical cannabis certification by gender and age, with and without interaction (Continued)

\begin{tabular}{|c|c|c|c|c|}
\hline \multirow{2}{*}{$\begin{array}{l}\text { Primary } \\
\text { Condition }\end{array}$} & \multicolumn{2}{|c|}{ Model without interaction between age and gender } & \multicolumn{2}{|c|}{ Model with interaction between age and gender } \\
\hline & Coefficient $(95 \% \mathrm{Cl})$ & p-value & Coefficient $(95 \% \mathrm{Cl})$ & p-value \\
\hline Age & $-0.021(-0.024,-0.017)$ & $<0.001$ & $-0.019(-0.024,-0.014)$ & $<0.001$ \\
\hline Gender (Male) & $-0.708(-0.827,-0.590)$ & $<0.001$ & $-0.549(-0.896,-0.202)$ & 0.002 \\
\hline Interaction & NA & NA & $-0.004(-0.012,0.004)$ & 0.339 \\
\hline \multicolumn{5}{|l|}{ Muscle Spasms } \\
\hline Intercept & $-4.027(-4.240,-3.817)$ & $<0.001$ & $-4.320(-4.649,-4.000)$ & $<0.001$ \\
\hline Age & $-0.001(-0.005,0.003)$ & 0.542 & $0.005(-0.001,0.011)$ & 0.131 \\
\hline Gender (Male) & $0.113(-0.015,0.242)$ & 0.085 & $0.577(0.178,0.981)$ & 0.005 \\
\hline Interaction & NA & NA & $-0.010(-0.018,-0.002)$ & 0.016 \\
\hline \multicolumn{5}{|l|}{ ADD/ADHD } \\
\hline Intercept & $-3.030(-3.262,-2.800)$ & $<0.001$ & $-3.607(-3.991,-3.231)$ & $<0.001$ \\
\hline Age & $-0.036(-0.041,-0.031)$ & $<0.001$ & $-0.022(-0.031,-0.014)$ & $<0.001$ \\
\hline Gender (Male) & $0.535(0.385,0.688)$ & $<0.001$ & $1.359(0.915,1.809)$ & $<0.001$ \\
\hline Interaction & NA & NA & $-0.021(-0.032,-0.011)$ & $<0.001$ \\
\hline \multicolumn{5}{|l|}{ Chronic Nausea } \\
\hline Intercept & $-2.193(-2.404,-1.983)$ & $<0.001$ & $-2.076(-2.359,-1.795)$ & $<0.001$ \\
\hline Age & $-0.043(-0.048,-0.038)$ & $<0.001$ & $-0.046(-0.053,-0.039)$ & $<0.001$ \\
\hline Gender (Male) & $-0.341(-0.473,-0.207)$ & $<0.001$ & $-0.567(-0.955,-0.178)$ & 0.004 \\
\hline Interaction & NA & NA & $0.006(-0.004,0.016)$ & 0.224 \\
\hline \multicolumn{5}{|l|}{ Fibromyalgia } \\
\hline Intercept & $-4.434(-4.699,-4.176)$ & $<0.001$ & $-4.392(-4.671,-4.121)$ & $<0.001$ \\
\hline Age & $0.016(0.011,0.021)$ & $<0.001$ & $0.016(0.010,0.021)$ & $<0.001$ \\
\hline Gender (Male) & $-2.502(-2.758,-2.261)$ & $<0.001$ & $-2.868(-3.715,-2.069)$ & $<0.001$ \\
\hline Interaction & NA & NA & $0.007(-0.008,0.023)$ & 0.352 \\
\hline \multicolumn{5}{|l|}{ Headaches } \\
\hline Intercept & $-3.439(-3.686,-3.195)$ & $<0.001$ & $-3.632(-3.974,-3.298)$ & $<0.001$ \\
\hline Age & $-0.020(-0.025,-0.014)$ & $<0.001$ & $-0.015(-0.022,-0.008)$ & $<0.001$ \\
\hline Gender (Male) & $-0.272(-0.426,-0.118)$ & 0.001 & $0.091(-0.363,0.548)$ & 0.695 \\
\hline Interaction & NA & NA & $-0.009(-0.019,0.002)$ & 0.096 \\
\hline \multicolumn{5}{|l|}{ Epilepsy } \\
\hline Intercept & $-3.622(-3.889,-3.359)$ & $<0.001$ & $-3.720(-4.115,-3.334)$ & $<0.001$ \\
\hline Age & $-0.023(-0.028,-0.017)$ & $<0.001$ & $-0.020(-0.029,-0.012)$ & $<0.001$ \\
\hline Gender (Male) & $0.084(-0.082,0.253)$ & 0.323 & $0.242(-0.247,0.736)$ & 0.334 \\
\hline Interaction & NA & NA & $-0.004(-0.015,0.007)$ & 0.502 \\
\hline
\end{tabular}

Table 6 shows the results of logistic regression analysis for age and gender as predictors for primary conditions for 56,860 patients. Logistic regression was conducted for each primary condition compared to all other conditions to determine whether age and gender predict reporting the primary condition versus not reporting the primary condition. The coefficient column represents the magnitude of effect and direction of the predictor variable; a negative coefficient for age suggests that younger patients are more likely to report the primary condition, and a negative coefficient for gender suggests that females are more likely to report the primary condition. $\mathrm{Cl}=$ confidence interval

cannabis or who may already be seeking medical cannabis without their knowledge, demonstrating the need for practitioners to educate themselves and be prepared to discuss and provide their professional medical opinion. Secondly, these data demonstrate that patients seeking medical cannabis are complex patients who have more than a single ailment. While rigorous clinical trials are still needed to validate the use of medical cannabis for these conditions, real world data are also needed to describe these patients, as complex patients are more likely to be excluded from clinical trials evaluating the effectiveness of a medication (Hanlon et al. 2019). Finally, these data 
Table 7 Summary of comorbid conditions and all conditions reported by 61,379 patients seeking medical cannabis certification, by gender

\begin{tabular}{|c|c|c|c|}
\hline Condition & $\begin{array}{l}\text { Patients, n (\%) } \\
n=61,379\end{array}$ & $\begin{array}{l}\text { Male, } \mathrm{n}(\%) \\
n=33,651\end{array}$ & $\begin{array}{l}\text { Female, } n(\%) \\
n=23,209\end{array}$ \\
\hline \multicolumn{4}{|l|}{ Comorbid Conditions } \\
\hline Anxiety & $17,359(28.3 \%)$ & $8306(24.7 \%)$ & 7465 (32.2\%) \\
\hline Back \& Neck Problems & $14,550(23.7 \%)$ & 7539 (22.4\%) & $5658(24.4 \%)$ \\
\hline Insomnia & $14,247(23.2 \%)$ & $7108(21.1 \%)$ & $5689(24.5 \%)$ \\
\hline Depression & $13,413(21.9 \%)$ & 5859 (17.4\%) & $6130(26.4 \%)$ \\
\hline Unspecified Chronic Pain & 11,199 (18.2\%) & $5756(17.1 \%)$ & 4523 (19.5\%) \\
\hline Headaches & $8688(14.2 \%)$ & 3889 (11.6\%) & $4029(17.4 \%)$ \\
\hline Arthritis & $8600(14.0 \%)$ & $4105(12.2 \%)$ & $3793(16.3 \%)$ \\
\hline Muscle Spasms & 7832 (12.8\%) & $409(1.2 \%)$ & $3257(14.0 \%)$ \\
\hline Post Traumatic Stress Disorder & $6155(10.0 \%)$ & $2764(8.2 \%)$ & $2876(12.4 \%)$ \\
\hline Migraines & $6063(9.9 \%)$ & $2273(6.8 \%)$ & $3276(14.1 \%)$ \\
\hline ADD/ADHD & $4612(7.5 \%)$ & $2413(7.2 \%)$ & $1612(6.9 \%)$ \\
\hline Chronic Nausea & $4440(7.2 \%)$ & $1892(5.6 \%)$ & $2268(9.8 \%)$ \\
\hline Fibromyalgia & $1809(2.9 \%)$ & $277(0.8 \%)$ & $1387(6.0 \%)$ \\
\hline Cancer Related Pain & $751(1.2 \%)$ & $348(1.0 \%)$ & $345(1.5 \%)$ \\
\hline Epilepsy & $388(0.6 \%)$ & $189(0.6 \%)$ & $185(0.8 \%)$ \\
\hline \multicolumn{4}{|l|}{ Total Reported Conditions } \\
\hline Chronic Pain & $35,016(57.0 \%)$ & $19,920(59.2 \%)$ & $13,233(57.0 \%)$ \\
\hline Anxiety & $25,639(41.8 \%)$ & $12,255(36.4 \%)$ & $10,689(46.1 \%)$ \\
\hline Back \& Neck Problems & $18,519(30.2 \%)$ & $5638(29.9 \%)$ & $4858(29.2 \%)$ \\
\hline Insomnia & $16,343(26.6 \%)$ & $10,045(24.7 \%)$ & $6783(27.4 \%)$ \\
\hline Depression & $14,662(23.9 \%)$ & $5254(19.1 \%)$ & 4841 (28.4\%) \\
\hline Post Traumatic Stress Disorder & $11,298(18.4 \%)$ & $8295(16.8 \%)$ & $6362(20.9 \%)$ \\
\hline Arthritis & 10,995 (17.9\%) & $1130(15.6 \%)$ & 1067 (20.9\%) \\
\hline Headaches & $9395(15.3 \%)$ & $6434(12.6 \%)$ & $6600(18.7 \%)$ \\
\hline Muscle Spasms & $8870(14.5 \%)$ & $2772(14.0 \%)$ & $3932(15.7 \%)$ \\
\hline Migraines & 7308 (11.9\%) & $4718(8.2 \%)$ & 3641 (16.9\%) \\
\hline ADD/ADHD & $5614(9.1 \%)$ & $3037(9.0 \%)$ & $1847(8.0 \%)$ \\
\hline Chronic Nausea & $5366(8.7 \%)$ & $2369(7.0 \%)$ & $2687(11.6 \%)$ \\
\hline Fibromyalgia & $2535(4.1 \%)$ & 347 (1.0\%) & $1984(8.5 \%)$ \\
\hline Cancer Related Pain & $2392(3.9 \%)$ & $4245(3.4 \%)$ & $4336(4.6 \%)$ \\
\hline Epilepsy & $1014(1.7 \%)$ & $561(1.7 \%)$ & 409 (1.8\%) \\
\hline
\end{tabular}

Table 7 reports the top 15 comorbid and total conditions by the total sample and by gender. Patients could report multiple comorbid conditions for which they were seeking medical cannabis. Total reported conditions summarizes the combined primary conditions and comorbid conditions. Patients could not report the same condition for both their primary condition and a comorbid condition. Percentages are calculated from the respective sample size for each column. $A D D$ attention deficit disorder, $A D H D$ attention deficit hyperactivity disorder

highlight the potential utility of medical cannabis and how it is currently utilized for treatment of multiple conditions with which a patient is suffering.

Medication use and average number of medications increased with age; however, patients reported medication use less than the general US population overall. Findings from the National Health and Nutrition Examination Survey reported that $83.6 \%$ of adults aged 60 and over used prescription medication in the previous 30 days, compared to only $56.4 \%$ of our sample aged 60 and older. For adults aged 40-59, our sample also reported less medication use; $48.3 \%$ compared to $59.5 \%$ (Martin et al. 2015). This difference may be a result of patients underreporting their medications at the clinic, or medication information not being correctly transcribed into the software from practitioners' notes. Alternatively, it may 
Table 8 Summary of "other" conditions each representing less than $1.0 \%$ of the total sample of patients seeking medical cannabis certification

\begin{tabular}{|c|c|}
\hline Condition & $\begin{array}{l}\text { Patients, n (\%) } \\
n=6519\end{array}$ \\
\hline Neuropathic Pain & $580(0.9 \%)$ \\
\hline Spinal Cord Injury/Disease & $574(0.9 \%)$ \\
\hline Glaucoma & $480(0.8 \%)$ \\
\hline Crohn's Disease & $472(0.8 \%)$ \\
\hline Stress & $418(0.7 \%)$ \\
\hline Multiple Sclerosis & $396(0.6 \%)$ \\
\hline Irritable Bowel Syndrome & $364(0.6 \%)$ \\
\hline Mood Disorders & $271(0.4 \%)$ \\
\hline Acute Pain & $253(0.4 \%)$ \\
\hline Colitis & $244(0.4 \%)$ \\
\hline HIV/AIDS & $224(0.4 \%)$ \\
\hline Opiate Dependence & $183(0.3 \%)$ \\
\hline Scoliosis & $156(0.3 \%)$ \\
\hline Appetite Stimulation & $152(0.2 \%)$ \\
\hline Parkinson's Disease Symptoms & $148(0.2 \%)$ \\
\hline Hepatitis C & $133(0.2 \%)$ \\
\hline Chemotherapy Induced Nausea & $108(0.2 \%)$ \\
\hline Autism & $57(0.1 \%)$ \\
\hline Cachexia/Wasting Syndrome & $56(0.1 \%)$ \\
\hline Movement Disorder & $46(0.1 \%)$ \\
\hline Anorexia & $42(0.1 \%)$ \\
\hline Obsessive Compulsive Behaviour & $41(0.1 \%)$ \\
\hline Tremors & $38(0.1 \%)$ \\
\hline Alzheimer's Disease & $26(0.0 \%)$ \\
\hline Bipolar Disorder & $25(0.0 \%)$ \\
\hline Tourette's Syndrome & $10(0.0 \%)$ \\
\hline Other & $1022(2.0 \%)$ \\
\hline
\end{tabular}

Table 8 reports the "other" conditions reported in Table 5 that each represent less than $1.0 \%$ of the total sample. Percentages are given out of the total sample (61,379 patients). There are over 200 unique conditions that were manually entered into the database by clinic staff that are categorized as "Other" in this Table. HIV human immunodeficiency viruses, AIDS acquired immunodeficiency syndrome

show a true difference in characteristics between the general US population and those accessing medical cannabis. The latter may suggest that those accessing medical cannabis may be doing so in lieu of using traditional pharmaceutical medications; however, this theory contradicts results of a study from 2018 that reported that medical cannabis users are more likely to use prescription medications (Caputi and Humphreys 2018). Reported medication use was not analyzed in reference to specific primary medical conditions for the purposes of this study, but identified it as an area of interest for future research. It is interesting to note that $26.1 \%$ of the sample did not report using medications or alternate therapies at the time of their initial assessment. This may demonstrate a limitation of the data, as there is potential that there is underreporting at the system level; however, this may also indicate that patients are seeking medical cannabis where other treatments have failed, which would benefit from further investigation.

When comparing our results to a study of 1746 patients attending assessment clinics in California in 2006, who were primarily male $(72.9 \%)$ and between the ages of $25-$ 54 (69.2\%) (Reinarman et al. 2011), it suggests that the medical cannabis patient population has evolved over time to include more females, and a wider range of ages; $40 \%$ of the sample who reported gender were female, and $31.5 \%$ of the patient population in this study were over the age of 54. The increasing age of medical cannabis users and increase in female users were also reported in a review completed by Fairman et al. (Fairman 2016). The high representation of Caucasians in this sample is consistent with the literature in which Caucasians represent the majority of medical cannabis users reported in other studies (77.0, 86.5, 61.5\%) (Sexton et al. 2016; Reinarman et al. 2011; Reiman 2007). This is substantiated by the fact that Caucasians are the racial majority in the US, particularly in the states where the clinics are located.

The median estimated household income in the ZIP codes where our patient sample resides was higher than the US median, $\$ 69,481$ compared to $\$ 61,937$ (Bureau UC 2019). When taking into consideration the median household income from just the included states, \$58,912 (US Income Statistics - Current Census Data for Zip Codes 2018), the median estimated household income from our sample was still higher; however, as the income data for our sample was a surrogate, this may be inflated and potentially inaccurate. Similar studies tend to report that income among medical cannabis users is lower than the average, which highlights the need for additional investigation (Sexton et al. 2016; Reiman 2007).

Data collected as part of the intake for patients in this retrospective study provide an interesting perspective on cannabis experience prior to seeking medical certification, as almost 70\% reported using cannabis prior to their certification. This number is substantially higher than the lifetime cannabis use estimate among Americans from the National Survey on Drug Use and Health, which reported a lifetime cannabis use of $45.3 \%$ in 2018 (2018 NSDUH Detailed Tables | CBHSQ Data 2019). Unfortunately, it is not known how many of the patients in the dataset had medical certification from a separate clinic or physician elsewhere prior to becoming a patient at a CB2 Insights clinic.

Strengths of this study include the large sample of patients accessing medical cannabis across 12 states. The consistent input of data at the clinics allowed for a 
comprehensive review of characteristics, and most importantly, provided data on all medical conditions for which patients sought medical cannabis, rather than just one per patient. Additionally, data collection was verified by medical professionals at the time of input. Limitations of this study primarily include missing data (i.e., a large number of patients for whom gender and race were not reported), a lack of ethnicity data, the absence of data on patients who did not qualify for medical cannabis certification and were not included in the registry, and the use of surrogate income data. Another limitation is that the data came from a single network of clinics, and do not represent patients in all states where medical cannabis is legal.

\section{Conclusion and future initiatives}

This retrospective study offers insight into the characteristics and commonly reported type and number of medical conditions among patients accessing medical cannabis in the US. It highlighted the conditions that patients are seeking medical cannabis for most often that would benefit from further clinical evidence; mainly pain conditions, anxiety, insomnia, depression and PTSD. This study also demonstrated that patients often use medical cannabis to treat more than one condition, which is important for the medical community to understand and be aware of, as well as the patients who may be turning to cannabis as a treatment option. This finding in particular raises questions that are important to investigate, including why patients use medical cannabis for multiple conditions and whether they use different products to treat their various symptoms. As this study explored demographic and medical characteristics from patients in 12 different states, an in-depth review comparing states with contrasting cannabis regulations would offer further insights into medical cannabis use and access in the US.

\section{Abbreviations}

CBD: cannabidiol; Cl: confidence interval; IQR: interquartile range; IRB: institutional review board; PTSD: post-traumatic stress disorder; SD: standard deviation; THC: $\Delta$-9-tetrahydrocannabinol; US: United States

\section{Acknowledgements}

The authors would like to thank Christopher Vannabouathong for assistance with the statistical analysis.

\section{Authors' contributions}

CS and KM conceptualized the study question. AG and JM completed the analysis and writing of the initial manuscript. CS and KM were integral in interpreting the data and writing and editing the manuscript. All authors read and approved the final manuscript.

\section{Funding}

This study was not funded by any external sources. Authors are employees of CB2 Insights and were compensated as per their contracts for the time to analyze the data and prepare the manuscript.

\section{Availability of data and materials}

The datasets used for this article are not publicly available due to patients' privacy. Data can be made available upon appropriate request to the authors.

\section{Ethics approval and consent to participate}

This research initiative was submitted for IRB review and determined to be exempt from IRB oversight by the Advarra IRB (Pro00042652) as this study had minimal risk, the data exports were void of patient identifiers, and it did not require direct patient contact.

\section{Consent for publication}

Not applicable.

\section{Competing interests}

The authors declare that they have no competing interests aside from being employees of CB2 Insights. All authors contributed to the manuscript as part of an internally guided project. CB2 Insights owns the data, and the authors are all employees of CB2 Insights. No external companies had input on the content of the manuscript, and all data were analyzed in an unbiased fashion. Apart from the authors, CB2 Insights did not play any role in the conduct or analysis of the study, the writing of the manuscript or the decision to publish.

Received: 27 April 2020 Accepted: 9 September 2020

Published online: 29 September 2020

\section{References}

2018 NSDUH Detailed Tables | CBHSQ Data. 2019 https://www.samhsa.gov/data/ report/2018-nsduh-detailed-tables. Accessed 27 Mar 2020.

Alsherbiny MA, Li CG. Medicinal Cannabis-Potential Drug Interactions. Med (Basel, Switzerland). 2018;6(1). https://doi.org/10.3390/medicines6010003.

Bertakis K, Azari R, Helms L, Callahan E, Robbins J. Gender differences in the utilization of health care services. J Fam $\operatorname{Pr} 2000 ; 49(2): 147-152$. https:// pubmed.ncbi.nlm.nih.gov/10718692/. Accessed 9 June 2020.

Boehnke KF, Gangopadhyay S, Clauw DJ, Haffajee RL. Qualifying conditions of medical cannabis license holders in the United States. Health Aff. 2019;38(2): 295-302. https://doi.org/10.1377/hlthaff.2018.05266.

Bonn-Miller MO, Boden MT, Bucossi MM, Babson KA. Self-reported cannabis use characteristics, patterns and helpfulness among medical cannabis users. Am J Drug Alcohol Abuse. 2014;40(1):23-30. https://doi.org/10.3109/00952990. 2013.821477.

Bureau UC. U.S. Median Household Income Up in 2018 From 2017. 2019. https:// www.census.gov/library/stories/2019/09/us-median-household-income-upin-2018-from-2017.html. Accessed 26 Sept 2019.

Buvinić M, Medici A, Fernández E, Torres AC. Gender differentials in health. The International Bank for Reconstruction and Development / The World Bank; 2006. http://www.ncbi.nlm.nih.gov/pubmed/21250310. Accessed 14 Aug 2020.

Caputi TL, Humphreys K. Medical marijuana users are more likely to use prescription drugs medically and nonmedically. J Addict Med. 2018;12(4): 295-9. https://doi.org/10.1097/ADM.0000000000000405.

DISA Global Solutions. Map of marijuana legality by state. Retrieved from URL https://disa.com/map-of-marijuana-legality-by-state. 2019. https://disa.com/ map-of-marijuana-legality-by-state.

Eurich DT, Hanlon JG, Boisvenue JJ, Meng H, Dyck JRB. A description of the medical Cannabis use in Ontario, Canada. Cannabis Cannabinoid Res. 2019; 4(2):131-5. https://doi.org/10.1089/can.2018.0036.

Fairman BJ. Trends in registered medical marijuana participation across 13 US states and District of Columbia. Drug Alcohol Depend. 2016;159:72-9. https:// doi.org/10.1016/j.drugalcdep.2015.11.015

Fraguas-Sanchez Al, Torres-Suarez Al. Medical use of cannabinoids. Drugs. 2018; 78(16):1665-703. https://doi.org/10.1007/s40265-018-0996-1.

Hanlon P, Hannigan L, Rodriguez-Perez J, et al. Representation of people with comorbidity and multimorbidity in clinical trials of novel drug therapies: an individual-level participant data analysis. BMC Med. 2019;17(1):201. https:// doi.org/10.1186/s12916-019-1427-1.

Institute of Medicine (U.S.). Marijuana and medicine: assessing the science base. Natl Acad Press https://doi.org/1017226/6376. 1999. https://doi.org/10.5860/ choice.37-2206.

Kaur R, Ambwani SR, Singh S. Endocannabinoid system: a multi-facet therapeutic target. Curr Clin Pharmacol. 2016;11(2):110-7. 
Klumpers LE, Thacker DL. A brief background on Cannabis: from plant to medical indications. J AOAC Int. 2019;102(2):412-20. https://doi.org/10.5740/jaoacint. 18-0208.

Kosiba JD, Maisto SA, Ditre JW. Patient-reported use of medical cannabis for pain anxiety, and depression symptoms: systematic review and meta-analysis. Soc Sci Med. 2019;233:181-92. https://doi.org/10.1016/j.socscimed.2019.06.005.

Legislatures NC of S. State Medical Marijuana Laws. https://www.ncsl.org/ research/health/state-medical-marijuana-laws.aspx. Published 2020.

Lu Y, Anderson HD. Cannabinoid signaling in health and disease. Can J Physiol Pharmacol. 2017;95(4):311-27. https://doi.org/10.1139/cjpp-2016-0346.

Maclntyre S, Ford G, Hunt K. Do women "over-report" morbidity? Men's and women's responses to structured prompting on a standard question on long standing illness. Soc Sci Med. 1999;48(1):89-98. https://doi.org/10.1016/ S0277-9536(98)00292-5.

Martin CB, Hales CM, Gu Q, Ogden CL. Prescription Drug Use in the United States, 2015-2016 Key Findings Data from the National Health and Nutrition Examination Survey; 2015. https://www.cdc.gov/nchs/data/databriefs/db334_ tables-508.pdf\#1. Accessed 3 Apr 2020.

Pacula RL, Smart R. Medical marijuana and marijuana legalization. Annu Rev Clin Psychol. 2017;13:397-419. https://doi.org/10.1146/annurev-clinpsy-032816045128.

Pertwee RG. Pharmacology of cannabinoid CB1 and CB2 receptors. Pharmacol Ther. 1997;74(2):129-80. https://doi.org/10.1016/s0163-7258(97)82001-3.

Pertwee RG, Howlett AC, Abood ME, et al. International union of basic and clinical pharmacology. LXXIX. Cannabinoid receptors and their ligands: beyond CB(1) and CB(2). Pharmacol Rev. 2010;62(4):588-631. https://doi.org/ 10.1124/pr.110.003004.

Reiman A. Medical Cannabis patients: patient profiles and health care utilization patterns. Complement Health Pract Rev. 2007;12(1):31-50. https://doi.org/10 1177/1533210107301834

Reinarman C, Nunberg H, Lanthier F, Heddleston T. Who are medical marijuana patients? Population characteristics from nine California assessment clinics. J Psychoactive Drugs. 2011;43(2):128-35. https://doi.org/10.1080/02791072. 2011.587700.

Salazar CA, Tomko RL, Akbar SA, Squeglia LM, Mcclure EA. Medical Cannabis Use among Adults in the Southeastern United States. Cannabis. 2019;2(1):53-65.

Seeman MV. Psychopathology in women and men: focus on female hormones. Am J Psychiatry. 1997;154(12):1641-7. https://doi.org/10.1176/ajp.154.12.1641.

Sexton M, Cuttler C, Finnell JS, Mischley LK. A cross-sectional survey of medical Cannabis users: patterns of use and perceived efficacy. Cannabis Cannabinoid Res. 2016;1 (1):131-8. https://doi.org/10.1089/can.2016.0007.

US Income Statistics - Current Census Data for Zip Codes. 2018. https://www. incomebyzipcode.com/. Accessed 27 Mar 2020.

Verbrugge LM, Wingard DL. Sex differentials in health and mortality. Health Matrix. 1987;5(2):3-19. https://doi.org/10.1300/j013v12n02_07.

Vuckovic S, Srebro D, Vujovic KS, Vucetic C, Prostran M. Cannabinoids and pain: new insights from old molecules. Front Pharmacol. 2018;9:1259. https://doi. org/10.3389/fphar.2018.01259.

Waldron I. Sex differences in illness incidence, prognosis and mortality: issues and evidence. Soc Sci Med. 1983;17(16):1107-23. https://doi.org/10.1016/02779536(83)90004-7.

Westergaard D, Moseley P, Sørup FKH, Baldi P, Brunak S. Population-wide analysis of differences in disease progression patterns in men and women. Nat Commun. 2019;10(1):1-14. https://doi.org/10.1038/s41467-019-08475-9.

Yu B, Chen X, Chen X, Yan H. Marijuana legalization and historical trends in marijuana use among US residents aged 12-25: results from the 1979-2016 National Survey on drug use and health. BMC Public Health. 2020;20(1):1-10. https://doi.org/10.1186/s12889-020-8253-4.

Zaller N, Topletz A, Frater S, Yates G, Lally M. Profiles of medicinal cannabis patients attending compassion centers in Rhode Island. J Psychoactive Drugs. 2015;47(1):18-23. https://doi.org/10.1080/02791072.2014.999901.

\section{Publisher's Note}

Springer Nature remains neutral with regard to jurisdictional claims in published maps and institutional affiliations.

Ready to submit your research? Choose BMC and benefit from:

- fast, convenient online submission

- thorough peer review by experienced researchers in your field

- rapid publication on acceptance

- support for research data, including large and complex data types

- gold Open Access which fosters wider collaboration and increased citations

- maximum visibility for your research: over $100 \mathrm{M}$ website views per year

At BMC, research is always in progress.

Learn more biomedcentral.com/submissions 